\title{
BMJ Antitubercular specific activity of open ibuprofen and the other 2-arylpropanoic acids using the HT-SPOTi whole-cell phenotypic assay
}

\author{
Juan D Guzman, ${ }^{1,2}$ Dimitrios Evangelopoulos, ${ }^{1,3}$ Antima Gupta, ${ }^{1}$ Kristian Birchall, ${ }^{4}$ \\ Solomon Mwaigwisya, ${ }^{3}$ Barbara Saxty, ${ }^{4}$ Timothy D McHugh, ${ }^{3}$ Simon Gibbons, ${ }^{2}$ \\ John Malkinson, ${ }^{2}$ Sanjib Bhakta ${ }^{1}$
}

To cite: Guzman JD, Evangelopoulos D, Gupta A, et al. Antitubercular specific activity of ibuprofen and the other 2-arylpropanoic acids using the HT-SPOTi wholecell phenotypic assay. BMJ Open 2013;3:e002672. doi:10.1136/bmjopen-2013002672

- Prepublication history and additional material for this paper is available online. To view these files please visit the journal online (http://dx.doi.org/10.1136/ bmjopen-2013-002672).

*JDG and DE contributed equally to this work.

Received 5 February 2013 Revised 1 May 2013 Accepted 14 May 2013

This final article is available for use under the terms of the Creative Commons Attribution Non-Commercial 2.0 Licence; see http://bmjopen.bmj.com

For numbered affiliations see end of article.

\section{Correspondence to} Dr Sanjib Bhakta; s.bhakta@bbk.ac.uk, sanjib.bhakta@ucl.ac.uk

\section{ABSTRACT}

Objectives: Lead antituberculosis (anti-TB) molecules with novel mechanisms of action are urgently required to fuel the anti-TB drug discovery pipeline. The aim of this study was to validate the use of the highthroughput spot culture growth inhibition (HT-SPOTi) assay for screening libraries of compounds against Mycobacterium tuberculosis and to study the inhibitory effect of ibuprofen (IBP) and the other 2-arylpropanoic acids on the growth inhibition of $M$ tuberculosis and other mycobacterial species.

Methods: The HT-SPOTi method was validated not only with known drugs but also with a library of 47 confirmed anti-TB active compounds published in the ChEMBL database. Three over-the-counter non-steroidal anti-inflammatory drugs were also included in the screening. The 2-arylpropanoic acids, including IBP, were comprehensively evaluated against phenotypically and physiologically different strains of mycobacteria, and their cytotoxicity was determined against murine RAW264.7 macrophages. Furthermore, a comparative bioinformatic analysis was employed to propose a potential mycobacterial target.

Results: IBP showed antitubercular properties while carprofen was the most potent among the 2-arylpropanoic class. A 3,5-dinitro-IBP derivative was found to be more potent than IBP but equally selective. Other synthetic derivatives of IBP were less active, and the free carboxylic acid of IBP seems to be essential for its anti-TB activity. IBP, carprofen and the 3,5dinitro-IBP derivative exhibited activity against multidrug-resistant isolates and stationary phase bacilli. On the basis of the human targets of the 2arylpropanoic analgesics, the protein initiation factor infB (Rv2839c) of $M$ tuberculosis was proposed as a potential molecular target.

Conclusions: The HT-SPOTi method can be employed reliably and reproducibly to screen the antimicrobial potency of different compounds. IBP demonstrated specific antitubercular activity, while carprofen was the most selective agent among the 2-arylpropanoic class. Activity against stationary phase bacilli and multidrugresistant isolates permits us to speculate a novel

\section{ARTICLE SUMMARY}

Article focus

- Lead antituberculosis (anti-TB) molecules with novel mechanisms of action are urgently required to fuel the anti-TB drug discovery pipeline.

- Whole-cell phenotypic screening has been employed to discover currently used therapeutic antibiotics, and it is still considered a crucial bioassay in the discovery of new antimicrobials for tackling global health challenges such as TB.

- Repurposing old drugs has emerged as a novel paradigm to develop drugs against infectious diseases particularly of the developing world, as it allows saving of time and resources during drug development. These molecules have an established safety profile, which has been documented through their exposure to a large and often diverse population.

\section{Key messages}

- We found that ibuprofen (IBP) and carprofen, two non-steroidal anti-inflammatory drugs currently used as pain relievers in humans and animals, respectively, displayed specific growth inhibitory properties against the Mycobacterium tuberculosis complex.

- Evaluation of different synthetic derivatives of IBP demonstrated that the free carboxylic acid was required for anti-TB activity.

- IBP, carprofen and a synthetic derivative of IBP namely 3,5-dinitro-IBP, showed inhibitory activity against multidrug-resistant $M$ tuberculosis clinical isolates and the stationary-phase Mycobacterium bovis BCG in the same concentration range as exponential-phase susceptible $M$ tuberculosis $\mathrm{H}_{37} \mathrm{Rv}$.

mechanism of antimycobacterial action. Further medicinal chemistry and target elucidation studies could potentially lead to new therapies against TB. 


\section{ARTICLE SUMMARY}

Strengths and limitations of this study

- We have established the feasibility of screening libraries of compounds against different microbial species using the highthroughput spot culture growth inhibition assay.

- We have demonstrated that the 2-arylpropanoic acids have specific growth inhibitory effects against members of the $M$ tuberculosis complex.

- Our study was limited in the screening of different physiological states of $M$ tuberculosis and it remains to be confirmed whether these compounds have activity against non-replicative populations or not.

- Future work will include the precise determination of the anti-TB mechanism of action of these compounds.

\section{BACKGROUND}

The global emergence of multidrug and extensively drug-resistant Mycobacterium tuberculosis (M/XDR-TB) ${ }^{1}$ strains poses a major threat to our ability to control tuberculosis (TB). There is an urgent need for lead candidates with novel mechanisms of action to fuel the current anti-TB drug discovery pipeline; however, the numerous target-based approaches originating from the boom of postgenomic research have unfortunately failed to deliver bioactive molecules for future development. Whole-cell phenotypic screening has been the method of choice for discovering most of the therapeutic antibiotics used today and it is still considered a crucial bioassay in the discovery of new antimicrobials for tackling global health challenges such as TB. The principal reason for this is that whole-cell screening interrogates all the biochemical targets simultaneously in a specific physiological context, a process more efficient than focusing on one target that may have no biological relevance. All the current antitubercular drugs in clinical development, such as OPC-67683 (delamanid), PA-824, TMC207 (bedaquiline), PNU-100480 (sutezolid) and SQ109, were discovered as a result of whole-cell screening while not a single novel anti-TB lead has yet emerged from target-based screening. ${ }^{2}$

The agar plate proportion method estimates the number of colony forming units (CFU). It is considered the gold standard in whole-cell screening assays and serves to determine the minimum inhibitory concentration (MIC) of a particular drug or inhibitor. Although the method is convenient, it tests the effect of a drug against a single viable cell rather than a mixed population of cells, which is more realistic to the host-infection setting. The agar proportion method is not, however, designed to handle a large number of samples. It requires considerable amounts of the inhibitor and can take more than a month for the antitubercular properties of a compound to be determined. A lower volume agar-based assay was initially introduced in 2004 by Bhakta $e t a \hat{l}$ for assessing the susceptibility of Mycobacterium bovis BCG wild-type and its mutants to isoniazid (INH). The spot culture growth inhibition (SPOTi) assay method has been enhanced in various studies using 6-well, 24-well and 48-well plates for screening growth inhibitors against mycobacteria. ${ }^{4-7}$ Of immediate importance, the methodology has also been independently employed for drug susceptibility testing (DST) of clinical isolates in a TB reference laboratory in the Netherlands. ${ }^{8}$

There is currently a renewed interest in re-purposing old drugs especially for treating infectious diseases, ${ }^{9}$ saving time, effort and expenses from a new drug development because of the existing knowledge of their pharmacological (PK/PD) profiles, toxicity and safety. ${ }^{10}$ For example, the neuroleptic drug thioridazine was successfully used for treating M/XDR-TB patients in 2010, and clinical trials are currently in progress. ${ }^{11} 12$ Disulfiram, which was initially developed for treating alcoholism, has received attention because of its potent activity against drug-resistant TB strains, raising the possibility of its clinical use as a repurposed anti-TB agent. ${ }^{13}$ Furthermore, a study published parallel to our investigation found that the non-steroidal anti-inflammatory drug (NSAID) oxyphenbutazone was cidal to the nonreplicative $M$ tuberculosis bacilli. ${ }^{14}$ Other off-patent drugs (or attrition candidates) may still be waiting on the chemical shelf for their anti-infective power to be discovered. These entities might also help to unlock previously neglected molecular targets against global infective health challenges.

In this work, the miniaturisation of the SPOTi assay to a 96-well format is described for the first time, focusing on its application to a laboratory-based screening of drugs and inhibitor libraries against an array of bacterial pathogens and discussing its advantages over conventional methods. The validation of the high-throughput SPOTi (HT-SPOTi) was carried out with antimicrobial drugs and inhibitors. Common over-the-counter (OTC) analgesics were screened, and surprisingly, ibuprofen (IBP) was found to display growth inhibitory properties against $M$ tuberculosis growth in vitro. Previous reports have found that IBP can inhibit the growth of not only dermatophytic fungi, ${ }^{15}$ but also Gram-positive bacteria at acidic $\mathrm{pH}^{16}$ Against $M$ tuberculosis, IBP was, however, found to be unable to decrease bacterial loads in the lung or spleen when administered at doses of 10, 20 or $40 \mathrm{mg} / \mathrm{kg}$ in a murine infection model. More importantly, the sterilising activity of pyrazinamide (PZA) increased significantly when administered concomitantly with IBP or aspirin at $20 \mathrm{mg} / \mathrm{kg} .{ }^{17}$ In this work, a comprehensive spectrum of activity study was performed by evaluating members of the 2-arylpropanoic class against a different array of bacterial species. Synthetic chemical modifications of IBP were also made in order to attempt to elucidate any key structural requirements for activity. This first report tries to underline the anti-TB potential of the 2-arylpropanoic class, raising further interest in their medicinal chemistry and the study of their mechanism(s) of action as specific antitubercular agents. 


\section{METHODS}

\section{Small molecules}

All commercially available drugs used in this study were purchased from Sigma and dissolved in either cell biology-grade dimethyl sulfoxide (DMSO) or sterile deionised water. A collection of 47 compounds was purchased following shortlisting procedures applied to compounds identified as TB actives in publicly available phenotypic screening data. Pipeline Pilot (Accelrys Software Inc) was used to process this data, first, by combining data from ChEMBL (http://www.ebi.ac.uk/ chembl/) and PubChem (pubchem.ncbi.nlm.nih.gov), identifying 6625 unique compounds with an MIC $\leq 100 \mu \mathrm{M}$. Of these, 1283 compounds with any of the following undesirable physicochemical properties were removed: molecular weight greater than 600 , more than six rings, the presence of rings larger than seven atoms, more than six H-bond donors, more than $12 \mathrm{H}$-bond acceptors, more than 11 freely rotatable non-terminal bonds, more than seven non-contiguous rotatable bonds, the presence of atoms other than $\mathrm{C}, \mathrm{H}, \mathrm{N}, \mathrm{O}, \mathrm{P}$, $\mathrm{S}$ or halogens, more than two charged atoms, a net formal charge of more than +1 or less than -1 , and finally a cLogD of more than 6 or less than -1 . A further 334 compounds with undesirable substructures, defined as SMARTS by Pearce, ${ }^{18}$ were removed. Additional criteria including predicted solubility, structural diversity and commercial availability were considered when manually shortlisting the 47 compounds that were eventually purchased and screened using the 96-well SPOTi assay.

\section{Bacteria}

The bacterial strains used in this study were $M$ tuberculosis $\mathrm{H}_{37} \mathrm{Rv}$ (ATCC27294), $M$ bovis BCG (ATCC35734), $M$ aurum (ATCC23366), $M$ neoaurum (ATCC25795), $M$ smegmatis $\mathrm{mc}^{2} 155$ (ATCC700084) Staphylococcus aureus (ATCC25923), $S$ aureus strain (EMRSA-16), a clinical isolate kindly donated by $\mathrm{Dr}$ Paul Stapleton, Pseudomonas putida (ATCC12633) and Escherichia coli DH5 $\alpha$ (ATCC53868). Rhodococcus equi RHA1 was a generous gift from Professor Edith Sim. The MDR M tuberculosis strains used in this study were clinical isolates collected from the Royal Free Hospital, National Health Sevice Trust, London. Strain 11 : 139 was resistant to ethambutol (EMB), INH and rifampin (RIF), strain $11: 169$ was resistant to all first-line drugs and $11: 368$ was resistant to INH, RIF and streptomycin (STR).

Middlebrook 7H9 broth supplemented with $10 \%$ oleic acid, albumin, dextrose and catalase (OADC) was used for the growth of $M$ tuberculosis $\mathrm{H}_{37} \mathrm{Rv}$. Middlebrook $7 \mathrm{H} 9$ broth supplemented with $0.02 \%(v / v)$ glycerol, $0.05 \%$ $(v / v)$ tween-80 and $10 \%(v / v)$ albumin, dextrose and catalase was used for the growth of $M$ bovis BCG and $M$ aurum. $S$ aureus strains and $P$ putida were grown in nutrient broth and E coli in Luria-Bertani (LB) broth. All cultures were initiated from a cryopreserved glycerol stock, passaged twice for growth uniformity and grown until the mid-exponential phase at $37^{\circ} \mathrm{C}$ (actively dividing stage of bacterial growth) prior to the SPOTi assay. $M$ bovis BCG was grown in a rolling bottle at $2 \mathrm{rpm}$ using a $100 \mathrm{~mL}$ volume of supplemented liquid media. $M$ tuberculosis $\mathrm{H}_{37} \mathrm{Rv}$ was grown as a standing culture in $10 \mathrm{~mL}$ supplemented liquid media. $M$ aurum, $S$ aureus strains and $E$ coli were grown at $180 \mathrm{rpm}$ as shaking cultures in $10 \mathrm{~mL}$ of liquid media. $R$ equi RHA1 was grown in nutrient broth at $30^{\circ} \mathrm{C}$ with $180 \mathrm{rpm}$ shaking. A late stationary-phase $M$ bovis BCG culture was prepared by culturing exactly in the conditions described by tightly closing the lid of the rolling bottle, and incubating for 100 days before the assay.

\section{Drug susceptibility}

The drugs used in this study were dissolved at a final concentration of $50 \mathrm{~g} / \mathrm{L}$. Serial dilution was performed in a sterile, thin 96-well frosted subskirted microtitre plate that acted as a master plate. A column containing only DMSO was also included. Two microlitres of each of the diluted compounds were then transferred into sterile 96 -well plates. The plates were filled up to $200 \mu \mathrm{L}$ with agar-based media. Middlebrook 7H10 supplemented with $0.5 \%(v / v)$ glycerol and $10 \%(v / v)$ OADC was used for mycobacterial species. Nutrient agar media were used for $S$ aureus, $P$ putida and $R$ equi RHA1 strains, whereas LB agar was used for $E$ coli. The agar-based media were prevented from solidifying by using a hot plate at $50^{\circ} \mathrm{C}$ with constant stirring. The distribution of the agar media into the 96 wells was achieved using the MultidropCombi microplate dispenser (Thermo-Fisher Scientific). Plates were dried and a diluted inoculum of bacteria was applied ( $2 \mu \mathrm{L}$ of $\sim 10^{5} \mathrm{CFU} / \mathrm{mL}$ ) into each well by either the use of a single pipettor or by using the MultidropCombi. Plates were subsequently incubated at $37^{\circ} \mathrm{C}$ overnight $(16 \mathrm{~h})$ for $S$ aureus strains, $P$ putida and $E$ coli, 5 days for $M$ aurum and 2 weeks for $M$ bovis BCG and $M$ tuberculosis strains. Plates were incubated at $30^{\circ} \mathrm{C}$ overnight $(16 \mathrm{~h})$ for $R$ equi RHA1. The plates were then observed and MIC values were determined as the lowest concentration of the drug where no bacterial growth was observed.

The antibiotic susceptibility in acidic stress was observed according to a previously described method. ${ }^{19}$ $M$ neoaurum $(\mathrm{OD} \sim 1.0)$ cells were washed with phosphate-buffered saline $\mathrm{pH} 7.0$ twice before being stressed by placing in an acidic environment of Sauton's liquid medium $\mathrm{pH} 5.8$ or 7.0 for $1 \mathrm{~h}$ at $37^{\circ} \mathrm{C}$. Stressed cells $\left(2 \mu \mathrm{L}\right.$ of $10^{6}$ cells $\left./ \mathrm{mL}\right)$ were spotted onto 24-well plates containing Sauton's agar medium at pH 5.8 and 7.0 with antibiotic concentrations ranging from 0,20 , $30,40,50,60,65,70,80,90,100$ to $200 \mathrm{mg} / \mathrm{L}$.

The late stationary phase cells were obtained in a rolling bottle by tightly closing the lid of an $M$ bovis $\mathrm{BCG}$ culture in $100 \mathrm{~mL}$ of supplemented Middlebrook 7H9. The lid remained tightly closed for 100 days and then the SPOTi experiment was performed on 24-well plates 
with supplemented Middlebrook 7H10, using four different dilutions of the 100-day-old bacterial culture (neat, $10^{-1}, 10^{-2}$ and $10^{-3}$ ).

\section{Growth curves and CFU counting}

The growth curves were determined by measuring optical density at $600 \mathrm{~nm}\left(\mathrm{OD}_{600}\right)$ of $M$ bovis BCG cultures grown in $100 \mathrm{~mL}$ of supplemented Middlebrook $7 \mathrm{H} 9$, every day for 2 weeks. The concentrations of inhibitors used were $90(1 \times \mathrm{MIC})$ and $180 \mathrm{mg} / \mathrm{L}(2 \times \mathrm{MIC})$ for IBP, $65(1 \times \mathrm{MIC})$ and $130 \mathrm{mg} / \mathrm{L}(2 \times \mathrm{MIC})$ for carprofen and $50 \quad(1 \times \mathrm{MIC})$ and $100 \mathrm{mg} / \mathrm{L} \quad(2 \times \mathrm{MIC})$ for 3,5 -dinitro-IBP. One experiment was performed by adding the inhibitors before inoculation, while another experiment was performed by adding the inhibitors at the early-exponential phase of bacterial growth when the $\mathrm{OD}_{600}$ of the control was 0.6. CFU were measured by spreading (in triplicate) $100 \mu \mathrm{L}$ of different dilutions $\left(10^{-4}, 10^{-5}, 10^{-6}, 10^{-7}, 10^{-8}\right)$ of the bacterial cultures in Petri dishes containing $25 \mathrm{~mL}$ of supplemented Middlebrook 7H10. The Petri dishes were incubated at $37^{\circ} \mathrm{C}$ for 3 weeks and the number of colonies was counted. For the first experiment, when the inhibitors were added before inoculation, the CFU of all samples were analysed when the $\mathrm{OD}_{600}$ of the control was 0.8 . For the early-exponential phase experiment, CFU was determined for all samples $24 \mathrm{~h}$ after the addition of the inhibitors.

\section{Synergism}

The synergistic effect of IBP, carprofen and 3,5-dinitroIBP was examined in combination with INH, EMB and RIF against $M$ tuberculosis $\mathrm{H}_{37} \mathrm{Rv}$. The assay was conducted in a 48-well microtitre plate using a SPOTi checkerboard distribution. The compounds were serially diluted in DMSO to include MIC and sub-MIC concentrations. Each row of the 48-well plate contained different concentrations of the IBP derivatives and each column contained different concentrations of the first-line drug. The checkerboard was constructed by adding $1 \mu \mathrm{L}$ of each of the stock concentrations to the corresponding well and then dispensing $1 \mathrm{~mL}$ of warm $\left(55^{\circ} \mathrm{C}\right)$ Middlebrook $7 \mathrm{H} 10$ agar medium supplemented with $10 \%(v / v)$ OADC using the MultidropCombi Reagent Dispenser (Thermo-Fisher Scientific). The plates were then spotted with $M$ tuberculosis $\mathrm{H}_{37} \mathrm{Rv}$ as previously described. The plates were incubated in sealed bags at $37^{\circ} \mathrm{C}$ for 2 weeks and Fractional Inhibitory Concentration Indices (FICI) values were calculated using the following formula:

$$
\mathrm{FICI}=\frac{\mathrm{MIC}_{\mathrm{A}} \text { in presence of } \mathrm{B}}{\mathrm{MIC}_{\mathrm{A}}}+\frac{\mathrm{MIC}_{\mathrm{B}} \text { in presence of } \mathrm{A}}{\mathrm{MIC}_{\mathrm{B}}}
$$

An FICI value $\leq 0.5$ indicated synergism; a value between 0.5 and 4.0 indicated no interaction; and a value higher than 4.0 indicated antagonism.
Cytotoxicity and macrophage-infection model

The cytotoxicity assay on mouse macrophage cells (RAW 264.7) was performed according to a method described previously. ${ }^{19}$ The intracellular inhibition assay using $M$ aurum as a surrogate and RAW 264.7 macrophages was performed as described. ${ }^{19}$ Briefly, the intracellular inhibition assay was performed by infecting $5 \times 10^{5}$ macrophage cells/well with $M$ aurum in a 10:1 multiplicity of infection for $1 \mathrm{~h}$ at $37^{\circ} \mathrm{C}$ in 24-well plates. The culture was washed with RPMI-1640 three times and incubated with different concentrations of the compounds $(0,0.39$, $1.5,6.25,25$ and $100 \mathrm{mg} / \mathrm{L})$ in RPMI- 1640 media. Following incubation for $48 \mathrm{~h}$, the cells were washed twice with RPMI-1640 and lysed in $500 \mu \mathrm{L}$ of distilled water at room temperature for $10 \mathrm{~min}$. The lysed cells were centrifuged and resuspended into $50 \mu \mathrm{L}$ of distilled water, and then $5 \mu \mathrm{L}$ was spotted onto the 24-well plates containing Middlebrook 7H10 agar. The plates were incubated at $37^{\circ} \mathrm{C}$ for 5 days to determine intracellular survival.

\section{Protein homology searching using bioinformatics}

Using a literature search, the reported molecular targets of IBP and the other 2-arylpropanoic acids were identified in humans and their protein amino acid sequences retrieved from the UniProt protein database (http:// www.uniprot.org). These sequences were then used to search for the existence of homologous proteins in mycobacteria and in other bacterial species. The blastp algorithm at the NCBI BLAST server (http://www.blast. ncbi.nlm.nih.gov) was employed and an $\mathrm{E}_{\text {value }}$ cut-off of $<0.001$ was considered for a protein hit to be significant. Furthermore, the pairwise sequence alignment of the possible human target with the identified mycobacterial homologue was performed using the MAFFT (Multiple Alignment using Fast Fourier Transform) algorithm at the EBI web server (http://www.ebi.ac.uk/Tools/msa/ mafft) and the alignment was visualised using ESPript (espript.ibcp.fr/ESPript/ESPript).

\section{RESULTS}

\section{Antibiotic susceptibility using HT-SPOTi}

A selection of 18 antibiotics were used, including: the four first-line anti-TB drugs INH, EMB, PZA and RIF; six second-line anti-TB drugs STR, ethionamide (ETH), p-aminosalicylic acid (PAS), D-cycloserine (DCS), ofloxacin (OFL) and kanamycin (KAN); three $\beta$-lactams, namely cephalosporin $\mathrm{C}$ (CEP), ampicillin (AMP) and penicillin $\mathrm{G}$ (PEN); five broad-spectrum antibiotics phosphomycin (PHO), bacitracin (BAC), gentamicin (GEN), vancomycin (VAN) and metronidazole (MET). Each antibiotic was tested in the range of $125-0.12 \mathrm{mg} / \mathrm{L}$ following a twofold dilution pattern against the virulent $M$ tuberculosis $\mathrm{H}_{37} \mathrm{Rv}$, two surrogate organisms $M$ aurum and $M$ bovis BCG, a Gram-positive susceptible strain of $S$ aureus, a clinical methicillin-resistant $S$ aureus isolate (EMRSA-16) and finally two Gram-negative bacteria, 
P putida and E coli. The schematic figure 1A summarises the experimental protocol and a typical result of the HT-SPOTi assay explicitly showing the presence or absence of microbial growth. The MIC values were recorded as the lowest concentration at which no bacterial growth was observed by the naked eye. All bacterial species were highly susceptible to STR and OFL, except for the EMRSA16 $S$ aureus isolate (figure 1B), whereas the Mycobacterium species were selectively inhibited by INH, EMB and PAS. This experiment validated the use of the HT-SPOTi assay for drug screening purposes as the results were found to be reproducible when using a different batch of drugs and microorganisms (greater than $95 \%$ of the determinations had the same MIC).

\section{Validation of the HT-SPOTi assay against a library of} inhibitors

Since one of the main difficulties in attaining efficacy against $M$ tuberculosis is achieving sufficient cell wall permeation, a focused set of 47 confirmed active compounds having MIC values $\leq 100 \mu \mathrm{M}$ was selected from the ChEMBL database. The compounds were shortlisted based on predicted physicochemical properties, substructural filters and commercial availability (see Methods section). When tested in the 96-well format HT-SPOTi assay against $M$ tuberculosis $\mathrm{H}_{37} \mathrm{Rv}$, out of 47 compounds, 5 had MIC values above $100 \mu \mathrm{M}, 11$ had MIC values between 100 and $33.3 \mu \mathrm{M}, 22$ had MIC values between 33.3 and $11.1 \mu \mathrm{M}, 6$ had MIC values between 11.1 and $3.7 \mu \mathrm{M}$ and 3 had MIC values below 3.7 $\mu \mathrm{M}$. Figure 1C shows the chemical structures of the four most potent hits together with their reported and experimental MIC values. All the chemical structures, ChEMBL IDs and MIC values can be found in the online supplementary figure $\mathrm{S} 1$.

The MIC values obtained using the 96-well plate HT-SPOTi method were consistently higher than those reported in the ChEMBL database (figure 1D), except for three compounds with ChEMBL ID 1454848, 233896 and 1418750. This comparison plot showed that most of the compounds were below the identity line (1:1 line), and three compounds were above the line. It was a
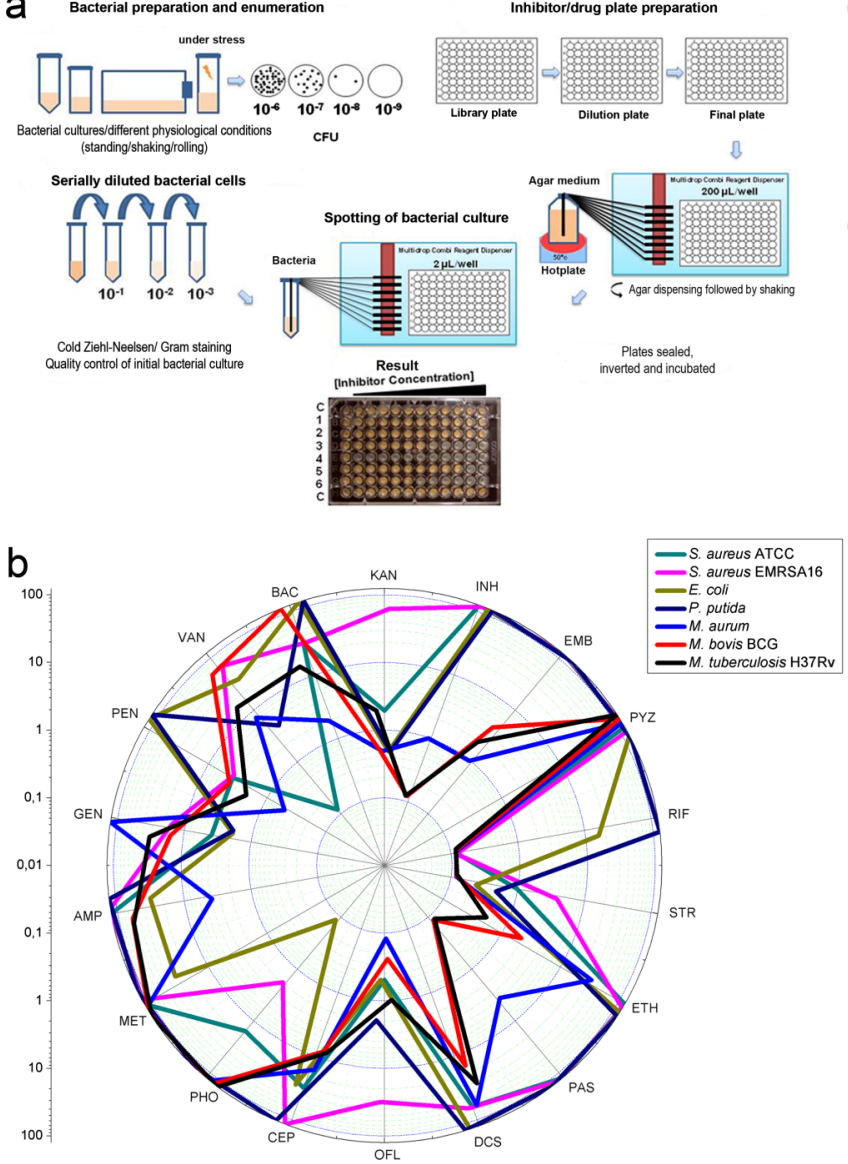

C

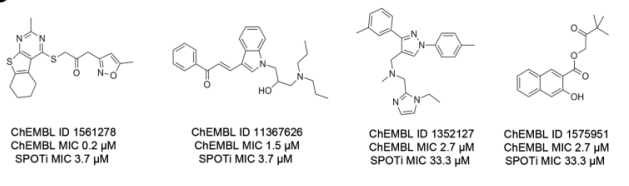

d

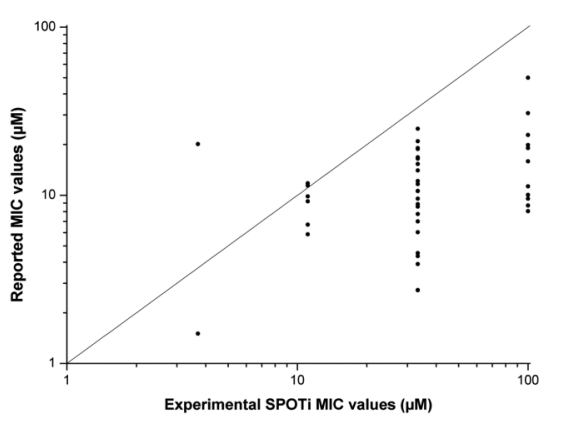

e

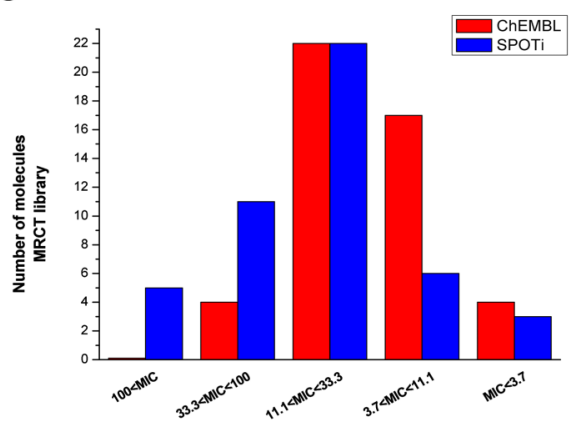

Figure 1 High-throughput spot culture growth inhibition (HT-SPOTi) is a reproducible minimum inhibitory concentration (MIC) determination method. (A) Schematic representation of the HT-SPOTi methodology. (B) Trends in MIC values for a set of selected antibiotics against various bacterial species using the HT-SPOTi assay. MICs were determined as the complete growth inhibition (no visible spot) at the depicted concentration. (C) Chemical structures of the four most active ChEMBL hits and comparison of their MIC values. (D) Correlation plot between reported values and experimental HT-SPOTi MIC values. MIC values greater than $100 \mu \mathrm{M}$ were not plotted. (E) MIC distribution histogram of the active ChEMBL focused set. 
interesting to note that ChEMBL 1454848 had a PAS unit covalently bound to a thiazolecoumarin moiety. Its MIC value was found to be $<20 \mu \mathrm{M}$ in both assays, confirming a high potency. The two most active molecules, ChEMBL 1561278 and 11367626 , were found to be potent (MIC $3.7 \mu \mathrm{M})$ in the 96-well SPOTi assay, while ChEMBL 1352127 and 1575951 were less active (figure 1C). The distribution of MIC, according to a different range of inhibitor concentration, was found to be similar between the available data and the HT-SPOTi assay (figure 1E)

\section{IBP and the other 2-arylpropanoic acids are growth inhibitors of $M$ tuberculosis}

The three most widely used OTC analgesics paracetamol, aspirin and IBP were tested for growth inhibition on $M$ bovis BCG using the SPOTi assay. The results were MIC values of $>500,250$ and $100 \mathrm{mg} / \mathrm{L}$, respectively, on the initial screen. Although a previous report mentioned a synergistic effect between IBP and PZA on a murine model, ${ }^{17}$ no literature data were found on the in vitro activity of IBP against mycobacteria. Therefore, we screened most of the available (Sigma-Aldrich) 2-arylpropanoic drugs such as IBP (1), naproxen (2), fenoprofen (3), ketoprofen (4), flurbiprofen (5), indoprofen $(\mathbf{6})$, carprofen (7), loxoprofen (8), and oxaprozin (9). Novel synthetic IBP derivatives, IBP methyl ester (10), IBP cyclopentylamide (11), IBP benzylamide (12), IBP 4-aminobenzylamide (13), IBP D-glutamic acid amide (14), 3,5-dinitro-IBP (15) and 3,5-dinitro-IBP methyl ester (16) were also prepared (figure 2A) in an attempt to elucidate structure-activity relationships. The synthetic procedures and analytical data can be found in the online supplementary information.

IBP (1) completely inhibited the in vitro growth of $M$ tuberculosis $\mathrm{H}_{37} \mathrm{Rv}$ at concentrations $>75 \mathrm{mg} / \mathrm{L}$ (table 1 ). Naproxen, fenoprofen, ketoprofen, flurbiprofen, indoprofen and oxaprozin were found to be less active with MIC values $>90 \mathrm{mg} / \mathrm{L}$ (table 1 ). Loxoprofen had an MIC value comparable to that of $\mathbf{1}$ but was around 700 times more expensive. Carprofen (7) was found to be more potent than IBP, with an MIC value of $40 \mathrm{mg} / \mathrm{L}$. Only 4, 6 and 9 were found to be inactive at the highest concentration tested $(\mathrm{MIC}>100 \mathrm{mg} / \mathrm{L})$. Similar trends of activity were observed against the vaccine strain $M$ bovis BCG and the opportunistic $M$ aurum and $M$ neoaurum species. Interestingly, lower MIC values were observed against $M$ neoaurum when tested in acidic $(\mathrm{pH}=5.8)$ compared with neutral $(\mathrm{pH}=7.0)$ Sauton's agar media.

All the commercial 2-arylpropanoic acids were halfinhibitory to the RAW264.7 macrophage cells at $1000 \mathrm{mg} / \mathrm{L}$, with the selectivity indices (SI) fluctuating between values of 10 and 25. Carprofen was the hit with the widest therapeutic window. When tested in a macrophage-infected model, most of the 2-arylpropanoic acids required a higher concentration to produce an effective killing of intracellular bacteria. Interestingly, 1 and 3 were active on the intracellular milieu with concentrations equal to or slightly higher than the MIC values.

The effect of the compounds was also tested against other microorganisms to assess their specificity. Neither $M$ smegmatis nor other acid-fast bacteria, such as $R$ equi RHA1 or Gram-positive $S$ aureus (susceptible and EMRSA strains) or Gram-negative $E$ coli JM109 or $P$ putida, were inhibited at a $100 \mathrm{mg} / \mathrm{L}$ concentration of compounds 1-7. We observed that this class of drugs was selective against slow-growing mycobacterial organisms, probably those with the facility to live in an intracellular environment.

Among the synthetic IBP derivatives, only 12, 13, 15 and $\mathbf{1 6}$ showed mycobacterial growth inhibition (table 2). The methyl ester of IBP (10) was inactive with an MIC value higher than $100 \mathrm{mg} / \mathrm{L}$, and the cyclopentylamide (11) was also inactive, indicating that the presence of a free carboxylic acid appears to play a substantial role in the antitubercular effect. The benzylamide moiety present in 12 and 13, although masking the free carboxylic acid, accorded activity but at the expense of being much more cytotoxic towards mammalian cells $(\mathrm{SI}=2.5)$. Another amide derivative of IBP, the dicarboxylic D-glutamic acid derivative 14, was inactive, a result that supported the requirement of a free propanoic acid carboxyl group for effective growth inhibition. In consequence, the potential modifications for improving the anti-TB activity of 1 were envisaged to be carried out either on the aromatic ring or on the isobutyl chain. The 3,5-dinitro-IBP derivative (15) was more active than IBP itself, achieving an MIC value of $30 \mathrm{mg} / \mathrm{L}$ against the virulent $\mathrm{H}_{37} \mathrm{Rv}$ strain. The compound was shown to be more cytotoxic than the parent compound 1; however, the selectivity index was the same. The introduction of a methyl ester functionality (giving 16) was detrimental to the anti-TB potential of $\mathbf{1 5}$, while substantially increasing its cytotoxicity.

The three most active 2-arylpropanoic acids, IBP (1), carprofen (7) and 3,5-dinitro-IBP (15), were screened against three MDR $M$ tuberculosis clinical isolates. The MIC values were in the range $20-50 \mathrm{mg} / \mathrm{L}$, comparable to the inhibitory values observed against the $\mathrm{H}_{37} \mathrm{Rv}$ strain (table 3). Furthermore, their synergistic or antagonistic actions in combination with the first-line anti-TB drugs INH, EMB and RIF were examined against $M$ tuberculosis $\mathrm{H}_{37} \mathrm{Rv}$ using a modified version of the SPOTi assay to represent a classic checkerboard assay format. There was no interaction between the 2-arylpropanoic acids IBP (1), carprofen (7) and 3,5-dinitro-IBP (15) and the first-line anti-TB drugs (data not shown).

For these three most active 2-arylpropanoic acid inhibitors, a growth curve was measured using the MIC $(1 \times \mathrm{MIC})$ and two times the MIC $(2 \times \mathrm{MIC})$ added to the liquid Middlebrook 7H9 media at the start of the experiment and in the early exponential phase of the growth of $M$ bovis BCG. The presence of carprofen (7) in the liquid Middlebrook $7 \mathrm{H} 9$ media at $70(1 \times \mathrm{MIC})$ or $140 \mathrm{mg} / \mathrm{L}(2 \times \mathrm{MIC})$ from the start of the experiment 
completely prevented the growth of $M$ bovis BCG (figure 2B), whereas the presence of 3,5-dinitro-IBP (15) at $1 \times$ MIC concentration $(50 \mathrm{mg} / \mathrm{L})$ did not show any effect on the growth and the culture evolved similarly to the DMSO control. The presence of IBP (1) at
$1 \times$ MIC concentration $(75 \mathrm{mg} / \mathrm{L})$ caused a slight delay in the growth but after a further $24 \mathrm{~h}$ of incubation, the OD values were equal to the DMSO control. However, when the liquid media contained $2 \times \mathrm{MIC}$ concentrations of both 1 and 15, the growth was completely prevented. a

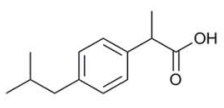

Ibuprofen (1)

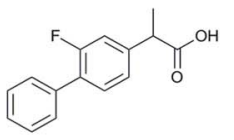

Flurbiprofen (5)

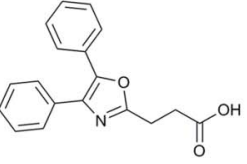

Oxaprozin (9)

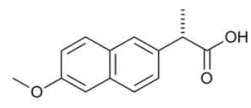

Naproxen (2)

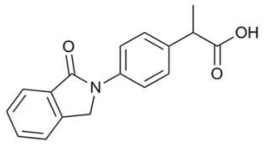

Indoprofen (6)

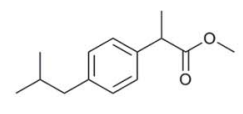

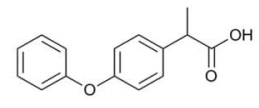

Fenoprofen (3)

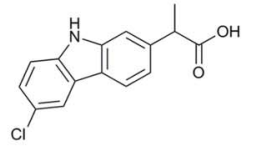

Carprofen (7)

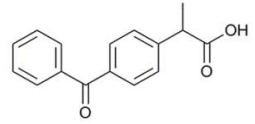

Ketoprofen (4)

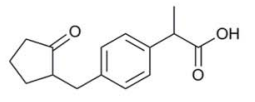

Loxoprofen (8)

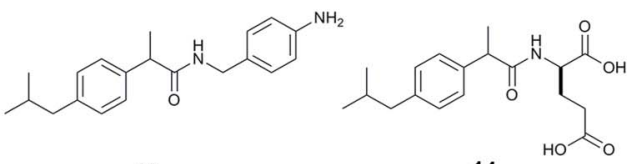

13

14 b

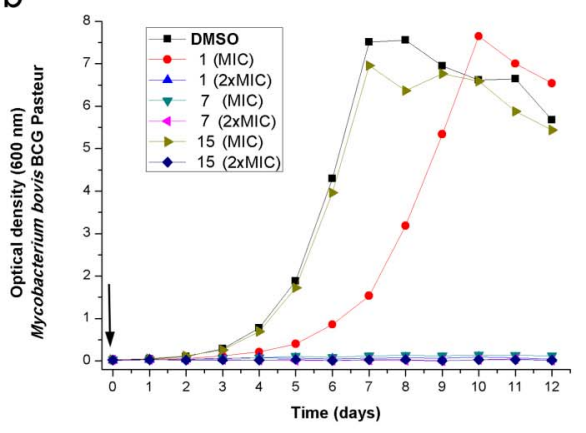

d

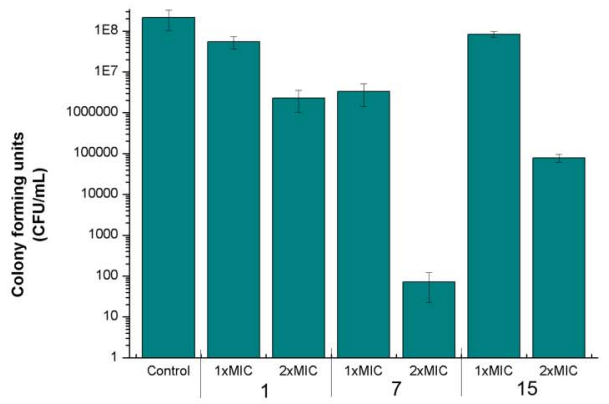

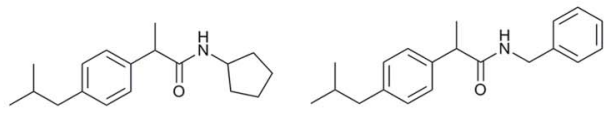

12

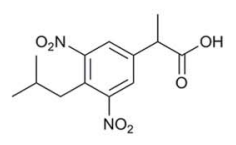

15

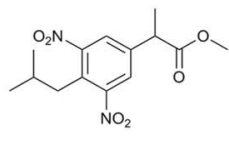

16

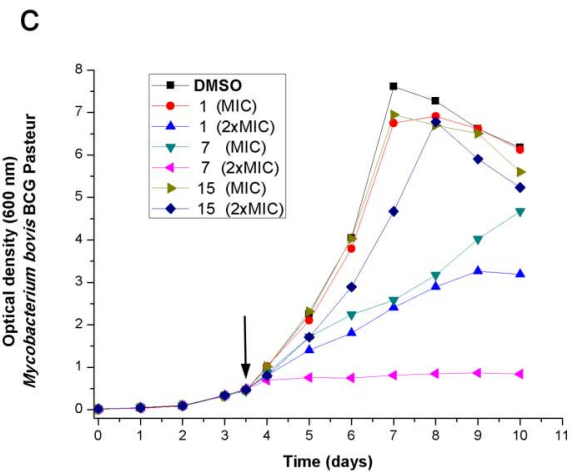

e

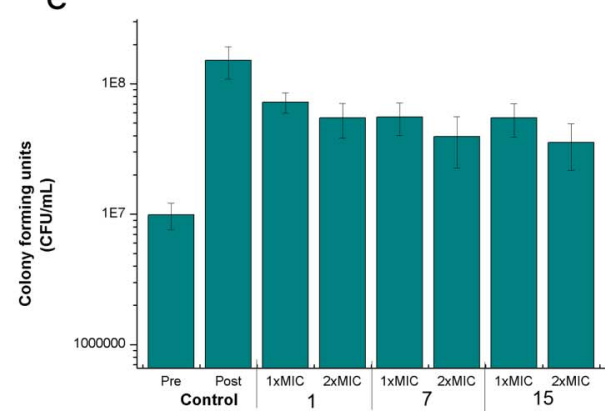

Figure 2 Ibuprofen and the related 2-arylpropanoic acids are inhibitors of slow-growing Mycobacterium. (A) Chemical structures of commercially available compounds $1-9$ and synthetically modified-IBP derivatives 10-16. (B) Growth curve of $M$ bovis BCG in liquid media growing with $1 \times$ minimum inhibitory concentration (MIC) and $2 \times \mathrm{MIC}$ of $\mathbf{1}, \mathbf{7}$ and $\mathbf{1 5}$ added before inoculation (as shown by the arrow). (C) Growth curve describing the same experiment with addition of the inhibitors at an early-exponential phase (as shown by the arrow). (D) Colony forming units (CFU) count of $M$ bovis BCG cells treated with $1 \times \mathrm{MIC}$ and $2 \times \mathrm{MIC}$ of 1 , 7 and 15 added before inoculation. CFU was determined simultaneously for all treatment when the OD600 of the control was 0.8. (E) CFU count determined simultaneously for all treatments $24 \mathrm{~h}$ after the addition of the inhibitors at the early-exponential phase. 
Table 1 Antimycobacterial, cytotoxic and anti-infective activities of commercially available 2-arylpropanoic acids (1-9)

\begin{tabular}{|c|c|c|c|c|c|c|c|c|c|}
\hline & \multicolumn{4}{|c|}{ MIC values against Mycobacterium (mg/L) } & \multicolumn{2}{|c|}{$\begin{array}{l}\text { MIC values } \\
\text { against } M \\
\text { neoaurum in } \\
\text { Sauton's agar } \\
\text { (mg/L) }\end{array}$} & \multirow{2}{*}{$\begin{array}{l}\text { Cytotoxicity } \\
\text { GIC }_{50}(\mathrm{mg} / \mathrm{L}) \\
\text { RAW264.7 }\end{array}$} & \multirow{2}{*}{$\begin{array}{l}\text { Selectivity } \\
\text { index SI } \\
\left(\text { GIC }_{50} /\right. \\
\text { MIC) }\end{array}$} & \multirow{2}{*}{$\begin{array}{l}\text { MIC values (mg/L) } \\
\text { against } M \text { aurum } \\
\text { grown inside } \\
\text { RAW264.7 }\end{array}$} \\
\hline & $\begin{array}{l}\text { M tuberculosis } \\
\mathrm{H}_{37} \mathrm{Rv}\end{array}$ & $\begin{array}{l}M \text { bovis } \\
\text { BCG }\end{array}$ & M aurum & M neoaurum & $\mathrm{pH}=5.8$ & $\mathrm{pH}=7.0$ & & & \\
\hline 1 & 75 & 90 & 65 & 65 & 20 & 200 & 1000 & 13.3 & 100 \\
\hline 2 & 90 & $>100$ & $>100$ & $>100$ & 50 & $>200$ & 1000 & 11.1 & $>100$ \\
\hline 3 & 100 & $>100$ & 100 & $>100$ & 20 & 200 & 1000 & 10 & 100 \\
\hline 4 & $>100$ & $>100$ & $>100$ & $>100$ & 65 & $>200$ & 1000 & $<10$ & $>100$ \\
\hline 5 & 90 & 70 & 70 & 65 & 20 & 70 & 1000 & 11.1 & $>100$ \\
\hline 6 & $>100$ & $>100$ & 90 & $>100$ & 50 & $>200$ & 1000 & $<10$ & $>100$ \\
\hline 7 & 40 & 65 & 40 & 40 & 20 & 40 & 1000 & 25 & 390 \\
\hline 8 & 70 & $\mathrm{Nd}$ & $\mathrm{Nd}$ & $\mathrm{Nd}$ & $\mathrm{Nd}$ & $\mathrm{Nd}$ & 1000 & 14.3 & $\mathrm{Nd}$ \\
\hline 9 & $>100$ & $\mathrm{Nd}$ & $\mathrm{Nd}$ & $\mathrm{Nd}$ & $\mathrm{Nd}$ & $\mathrm{Nd}$ & 1000 & $<10$ & $\mathrm{Nd}$ \\
\hline RIF & 0.05 & 0.05 & 0.1 & 1 & 0.4 & 0.4 & 700 & 60000 & 0.4 \\
\hline INH & 0.05 & 0.1 & 0.4 & 2 & 0.4 & 1.6 & 3000 & 14000 & 0.4 \\
\hline
\end{tabular}

In contrast, when the inhibitors were added at exactly the same concentrations in the early exponential phase of mycobacterial growth (figure $2 \mathrm{C}$; after 3.5 days of liquid rolling culture, $\left.\mathrm{OD}_{600} \sim 0.5\right), 1$ and 15 did not arrest mycobacterial growth. Remarkably, the $2 \times \mathrm{MIC}$ concentration of $\mathbf{7}$ completely stopped mycobacterial growth; however, the bacterial numbers did not change, maintaining a constant OD value throughout the experiment (even after 1 month of incubation). When 7 was added at the $1 \times$ MIC concentration, the growth rate was significantly reduced compared with the DMSO control. A similar decrease in the growth was observed when 1 was administered at a concentration of $180 \mathrm{mg} / \mathrm{L}(2 \times \mathrm{MIC})$.

The presence from the start of the experiment of the $2 \times$ MIC concentration of carprofen (7) notably affected

\begin{tabular}{|c|c|c|c|c|}
\hline & \multicolumn{2}{|c|}{$\begin{array}{l}\text { MIC values against } \\
\text { Mycobacterium (mg/L) }\end{array}$} & \multirow[b]{2}{*}{$\begin{array}{l}\text { Cytotoxicity } \\
\text { GIC }_{50}(\mathrm{mg} / \mathrm{L}) \\
\text { RAW264.7 }^{2}\end{array}$} & \multirow[b]{2}{*}{$\begin{array}{l}\text { Selectivity } \\
\text { index SI } \\
\left(\mathrm{GIC}_{50} / \mathrm{MIC}\right)\end{array}$} \\
\hline & $\begin{array}{l}\text { M tuberculosis } \\
\mathrm{H}_{37} \mathrm{RV}\end{array}$ & $\begin{array}{l}\text { M bovis } \\
\text { BCG }\end{array}$ & & \\
\hline 10 & $>100$ & $>100$ & 750 & $<7.5$ \\
\hline 11 & $>100$ & 100 & 325 & $<3.25$ \\
\hline 12 & 40 & 60 & 100 & 2.5 \\
\hline 13 & 90 & 80 & 200 & 2.2 \\
\hline 14 & $>100$ & $>100$ & $\mathrm{Nd}$ & $\mathrm{Nd}$ \\
\hline 15 & 30 & 50 & 400 & 13.3 \\
\hline 16 & 40 & $>100$ & 250 & 6.25 \\
\hline
\end{tabular}

IBP, ibuprofen; MIC, minimum inhibitory concentration; Nd, not determined. bacterial multiplication, achieving a reduction of $M$ bovis BCG cells of more than 6-log CFU compared with the DMSO control (figure 2D). This result demonstrates the potent prevention of mycobacterial growth by carprofen. At the $2 \times$ MIC concentration, the dinitro derivative $\mathbf{1 5}$ reduced the number of cells by more than 3-log CFU, whereas 1 decreased growth by only 1-log unit. When the compounds were added at the early exponential phase of growth, little effect on bacterial viability was observed after $36 \mathrm{~h}$. There was no decrease in bacterial CFU even for carprofen at $2 \times \mathrm{MIC}$, demonstrating little killing ability but rather a bacteriostatic effect (figure 2D).

MIC values were also dependent on the physiological condition of the inoculum (table 4). The MIC values of INH, RIF and EMB against the exponential-phase bacilli were significantly lower compared with the values against stationary-phase bacteria for all the bacterial dilutions tested. Interestingly the three most active 2-arylpropanoic acids, IBP (1), carprofen (7) and 3,5-dinitro-IBP (15), had exactly the same MIC values (80, 40 and $60 \mathrm{mg} / \mathrm{L}$, respectively) against both the late stationary phase bacilli and the exponential phase bacilli for the $10^{-3}$ bacterial dilution. When a higher number of bacterial cells was spotted, the similar effect of the 2-arylpropanoic acids against both exponential and stationary phase cells was less evident, but still observed. These results suggest that this class could be active against mycobacterial stages of low metabolic activity (eg, persistent or dormant cells).

It has been recognised that IBP and the other 2-arylpropanoic acids have multiple human biological targets, as demonstrated by their numerous therapeutic 
Table 3 MIC values of selected 2-arylpropanoic acids (1, 7 and 15) against clinical Mycobacterium tuberculosis multidrug resistant strains $11: 139,11: 169$ and $11: 368$

\begin{tabular}{|c|c|c|c|}
\hline & \multicolumn{3}{|c|}{$\begin{array}{l}\text { MIC values against MDR } M \text { tuberculosis } \\
\text { clinical isolates }(\mathrm{mg} / \mathrm{L})\end{array}$} \\
\hline & $11: 139$ & $11: 169$ & $11: 368$ \\
\hline 1 & 50 & 50 & 30 \\
\hline 7 & 40 & 50 & 20 \\
\hline 15 & 50 & 40 & 40 \\
\hline INH & 5 & 10 & 5 \\
\hline RIF & 5 & $>25$ & 25 \\
\hline EMB & 20 & 10 & 5 \\
\hline STR & 5 & $>25$ & 5 \\
\hline
\end{tabular}

All the MDR-strains were susceptible to kanamycin, amikacin, capreomycin and $\mathrm{p}$-aminosalicylic acid.

$\mathrm{EMB}$, ethambutol; INH, isoniazid; MIC, minimum inhibitory

concentration; PAS, $p$-aminosalicylic acid; RIF, rifampin.

applications, acting as analgesics and anti-inflammatories but also for treating neurodegenerative diseases and cancer. ${ }^{20-22}$ The classical molecular targets of these drugs are the two isoforms of cyclooxygenase (COX1 and COX2), which catalyse the transformation of arachidonic acid into the prostaglandins, which are essential molecules mediating the inflammatory response. The 2-arylpropanoic acids have been reported to inhibit different enzymes and receptors, namely COX1 and COX2, the subunits of the secretase receptor $\gamma$, the subunits of the peroxisome proliferator-activated receptor $\gamma$, the nuclear factor $\kappa$ and the Rho-GTPase. ${ }^{23} M$ tuberculosis $\mathrm{H}_{37} \mathrm{Rv}$ proteins that are homologous to the human targets were dissected by using a basic local alignment search tool (BLAST) of the NCBI online website, from the amino acid sequence of the human proteins. The analysis was extended to other sequenced mycobacterial and non-mycobacterial organisms (table 5). For most of the human targets of the 2-arylpropanoic acids, no significant sequence-homologue proteins were found in $M$ tuberculosis; however, for the human Rho-GTPase, a mycobacterial homologue with a high level of similarity (E value $10^{-5}$ ) was found (see online supplementary figure S2). This protein, known as Rv2839c, has been hypothetically annotated as a translation initiation factor
IF-2 (infB), being classified as an essential component of protein synthesis initiation. ${ }^{24} \mathrm{~A}$ homologue of the human Rho-GTPase was also identified in Mycobacterium leprae, suggesting that it performs an essential task, and therefore has been conserved through the genomic decay of this pathogen. This homologue protein was also detected in $M$ smegmatis; however, it was not present in either $S$ aureus or $E$ coli when a comparative genomic analysis was performed. Moreover, a significant homologue of the COX1 and COX2 human enzymes was identified only in the fast-growing $M$ smegmatis (table 5), a strain not inhibited by the 2-arylpropanoic acids, ruling out that a COX-related protein might be inhibited in mycobacteria.

\section{DISCUSSION}

Until now, the SPOTi assay has been used successfully to identify hits with antimycobacterial activity derived from natural and synthetic sources since $2004 .^{5-7}$ We describe here the automation and miniaturisation upgrade of the SPOTi assay. In addition, the use of the SPOTi assay has now been extended to other bacterial pathogens including Gram-positive and Gram-negative species. The HT-SPOTi assay has also been performed successfully using a dilution of fungal cultures for determining MICs of antifungal compounds (unpublished results). HT-SPOTi synergism or antagonism assays have been performed using a checkerboard distribution. By extension to the synergism/antagonism experiment, the possibility of rescue of bacterial growth in the presence or absence of certain medium components (such as carbon sources, metals, amino acids, proteins and others) can also be analysed, giving insight into the mechanism of action of a particular growth inhibitor. Furthermore, the use of a 96-well SPOTi assay enabled the screening of large libraries available from different existing collections retrospectively. Ultimately, as phenotypic screens have been successful tools for discovering potent antibacterial drugs, the HT-SPOTi methodology has the potential to identify new antimicrobial molecules with clinical relevance.

Table 4 MIC values of selected 2-arylpropanoic acids (1, 7 and 15) and first-line anti-TB drugs using different bacterial dilutions against exponential-phase (Log) and stationary-phase (Sta) Mycobacterium bovis BCG cultures

\section{MIC values against $M$ bovis BCG (mg/L)}

\begin{tabular}{|c|c|c|c|c|c|c|c|c|}
\hline \multirow{2}{*}{$\begin{array}{l}\text { Dilution } \\
\text { Physiological state }\end{array}$} & \multicolumn{2}{|l|}{ Neat } & \multicolumn{2}{|l|}{$10^{-1}$} & \multicolumn{2}{|l|}{$10^{-2}$} & \multicolumn{2}{|l|}{$10^{-3}$} \\
\hline & Log & Sta & Log & Sta & Log & Sta & Log & Sta \\
\hline 1 & $>100$ & $>100$ & 100 & $>100$ & 80 & 100 & 80 & 80 \\
\hline 7 & 80 & $>100$ & 60 & 80 & 60 & 80 & 40 & 40 \\
\hline 15 & 100 & $>100$ & 100 & 100 & 60 & 60 & 60 & 60 \\
\hline INH & 0.05 & $>10$ & 0.05 & $>10$ & 0.05 & $>10$ & 0.05 & $>10$ \\
\hline RIF & 0.05 & $>10$ & 0.01 & 10 & 0.01 & 10 & 0.01 & 1 \\
\hline EMB & 10 & $>10$ & 5 & $>10$ & 5 & $>10$ & 5 & $>10$ \\
\hline
\end{tabular}

EMB, ethambutol; INH, isoniazid; MIC, minimum inhibitory concentration; RIF, rifampin. 
Table 5 Putative potential molecular targets of the 2-arylpropanoic class in Mycobacterium tuberculosis based on homology of the human reported targets

\begin{tabular}{|c|c|c|c|c|c|}
\hline $\begin{array}{l}\text { IBPI } \\
\text { 2-arylpropanoic } \\
\text { acid molecular } \\
\text { target in } \\
\text { humans }\end{array}$ & $\begin{array}{l}\text { Function in } \\
\text { humans }\end{array}$ & $\begin{array}{l}\text { Homologues in } \\
\text { Mycobacterium } \\
\text { tuberculosis } \\
\mathrm{H}_{37} \mathrm{Rv}\end{array}$ & $\begin{array}{l}\text { Function in } \\
\text { Mycobacterium } \\
\text { tuberculosis }\end{array}$ & $\begin{array}{l}\text { Homologues in } \\
\text { Mycobacterium } \\
\text { leprae }\end{array}$ & $\begin{array}{l}\text { Homologues in } \\
\text { Mycobacterium } \\
\text { smegmatis }\end{array}$ \\
\hline COX-1 & Cyclooxygenase 1 & No & - & No & $\begin{array}{l}\text { MS6324 } \\
\left(E_{\text {value }} 10^{-19}\right)\end{array}$ \\
\hline cox-2 & Cyclooxygenase 2 & No & - & No & $\begin{array}{l}\text { MS6324 } \\
\left(E_{\text {value }} 10^{-19}\right)\end{array}$ \\
\hline Presenilin-1 & $\begin{array}{l}\text { Trans-membrane } \\
\gamma \text {-secretasesubunit }\end{array}$ & No & - & No & No \\
\hline $\mathrm{APH}-1 \mathrm{~A}$ & $\begin{array}{l}\gamma \text {-Secretase subunit } \\
1 \mathrm{~A}\end{array}$ & No & - & No & No \\
\hline PEN-2 & $\gamma$-Secretase subunit & No & - & No & No \\
\hline$N F-\kappa B$ & $\begin{array}{l}\text { Nuclear factor } \kappa \\
\text { enhancer of } \\
\text { activated B cells }\end{array}$ & No & - & No & No \\
\hline $\mathrm{APH}-1 \mathrm{~B}$ & $\begin{array}{l}\gamma \text {-Secretase subunit } \\
1 \mathrm{~B}\end{array}$ & $\begin{array}{l}\text { Rv2276 } \\
\left(E_{\text {value }} 0.0013\right)\end{array}$ & $\begin{array}{l}\text { Cytochrome P450-121 } \\
\text { CYP121 }\end{array}$ & No & No \\
\hline Nicastrin & $\gamma$-Secretase subunit & $\begin{array}{l}\text { Rv3411c } \\
\left(E_{\text {value }} 0.019\right)\end{array}$ & $\begin{array}{l}\text { Inosine-5-monophosphate } \\
\text { dehydrogenase guaB2 }\end{array}$ & No & No \\
\hline PPARG-1/2 & $\begin{array}{l}\text { Peroxisome } \\
\text { proliferator } \\
\text { activated-receptor } \gamma\end{array}$ & $\begin{array}{l}\text { Rv3146 } \\
\left(E_{\text {value }} 0.007\right)\end{array}$ & $\begin{array}{l}\text { NADH-ubiquinone } \\
\text { dehydrogenase subunit B }\end{array}$ & No & $\begin{array}{l}\text { MS2062 } \\
\left(E_{\text {value }} 0.007\right)\end{array}$ \\
\hline RHO-GTPase & Rho GTPase & $\begin{array}{l}\text { Rv2839c } \\
\left(E_{\text {value }} 10^{-5}\right)\end{array}$ & $\begin{array}{l}\text { Translation initiation factor } \\
\text { IF-2 }\end{array}$ & $\begin{array}{l}\text { ML1556 } \\
\left(E_{\text {value }} 0.005\right)\end{array}$ & $\begin{array}{l}\text { MS0758 } \\
\left(E_{\text {value }} 0.006\right)\end{array}$ \\
\hline
\end{tabular}

This table shows the homologous proteins found in mycobacterial organisms that share sequence similarity with recorded human targets of ibuprofen and other 2-arylpropanoic acids.

This assay possesses advantages over other classical and modern whole-cell phenotypic methods. Being an agar-based method, contamination can be easily monitored, resulting in more rigorous quality control in the early stages of hit identification. In addition, hydrophobic compounds are evenly distributed in the warm agar $\left(\sim 50^{\circ} \mathrm{C}\right)$ and on solidification, the lower mobility reduces the chances of aggregation, whereas lipophilic compounds tend to precipitate in liquid-based methods or do not diffuse well on the polar media used in the zone of inhibition assays. Some natural products are often coloured and thus can interfere with the final colorimetric read-out when using viability indicator dyes (eg, methyl thiazolyl tetrazolium or resazurin/ Alamar Blue). Additionally, some compounds, such as the flavonoids, possess antioxidant properties, are conjugated and can reduce the oxidised dyes used in the colorimetric assays, resulting in false positives. ${ }^{25} 26$ The HT-SPOTi assay also has the potential to be employed for the determination of DST of clinical isolates. As shown in figure 1B, the multidrug-resistant EMRSA-16 strain was clearly differentiated from the susceptible staphylococcal strain. The simplicity of the SPOTi method makes it useful in a basic diagnostic laboratory. We consider that the application of the HT-SPOTi assay in DST would contribute to the control of bacterial resistance, especially in rural areas where access to sophisticated medical equipment (such as the mycobacterial growth indicator tube or the GeneXpert MTB/ RIF) is often lacking. The prepared plates with antibiotics could be shipped to distant locations and then spotted with bacterial cultures in the local clinical microbiology laboratory. In this way, phenotypic examination of TB drug susceptibility could be diagnosed without the need for specialised instruments or expensive consumables.

From the three most widely used OTC analgesics (paracetamol, aspirin and IBP), IBP showed the highest activity against $M$ bovis BCG. Aspirin was inhibitory at a concentration of $250 \mathrm{mg} / \mathrm{L}$, while IBP completely inhibited the growth at $100 \mathrm{mg} / \mathrm{L}$. Both aspirin and IBP have been reported to exert in vivo synergistic effects with PZA in a murine model of TB infection, being able to reduce by more than 1 logarithmic unit the numbers of CFU with a dose of $20 \mathrm{mg} / \mathrm{kg}$ compared with treatment with PZA alone at $150 \mathrm{mg} / \mathrm{kg}$. ${ }^{17}$ However, both compounds were ineffective on their own, even at the highest dose tested of $40 \mathrm{mg} / \mathrm{kg}$. In a study on mice feeding with the highest dose of IBP $(1.36 \mathrm{~g} / \mathrm{kg}$ diet $)$, the maximal IBP plasma concentration attained was around $20 \mathrm{mg} / \mathrm{L}^{27}$; however, in humans, a high dose of $20-30 \mathrm{mg} / \mathrm{kg}$ achieved a plasma concentration of $66-72 \mathrm{mg} / \mathrm{L}{ }^{28}$ 
The maximum human daily dose of IBP is $3200 \mathrm{mg}$, and serious toxic effects appear with doses higher than 200-400 mg/kg. ${ }^{29}{ }^{30}$ IBP shows strong binding to plasma albumin and low binding to tissue proteins such as actin; as a consequence, IBP has a low volume of distribution of around $0.1-0.2 \mathrm{~L} / \mathrm{kg}$. IBP is incorporated into hybrid lipids, particularly modified triglycerides, and this effect actually enhances accumulation of IBP into adipose tissue. $^{31}$ In addition, IBP displays immunomodulatory effects, being able to decrease the levels of inducible nitric oxide synthase ${ }^{32}$ and the release of tumour nuclear factor $\alpha$ and interleukin $1 \beta$ in human mononuclear cells. ${ }^{33}$ These processes are of crucial significance in dealing with intracellular pathogens and specifically with M tuberculosis. ${ }^{34}{ }^{35}$ It is therefore possible that the administration of IBP concomitant with current anti-TB therapy could decrease the mycobacterial populations inside TB patients; an effect which has yet to be measured.

Carprofen (7) was by far the most potent 2-arylpropanoic acid against both $M$ tuberculosis $\mathrm{H}_{37} \mathrm{Rv}$ and $M$ bovis BCG with an MIC value of $40 \mathrm{mg} / \mathrm{l}$. This drug was less active against the fast-growing mycobacteria $M$ aurum and $M$ neoaurum (MIC $\sim 70 \mathrm{mg} / \mathrm{l}$ ) and inactive against $M$ smegmatis (MIC $>100 \mathrm{mg} / \mathrm{L}$ ) or the acid-fast bacillus $R$ equi RHA1. The specificity against the $M$ tuberculosis complex perhaps indicates an underlying biological mechanism that uniquely targets an essential protein of the $M$ tuberculosis complex while having less affinity for the same macromolecule in other bacterial species. Among the commercially available 2-arylpropanoic acids, carprofen had the better selectivity profile achieving SI values of 25, confirming its high antitubercular specificity.

In animals, carprofen (7) is widely used for treating pain and inflammation. ${ }^{36}$ It has high plasma concentration in cats, achieving levels from 25 to $50 \mathrm{mg} / \mathrm{L}$ after administration of a low dose of $4 \mathrm{mg} / \mathrm{kg}$ during the first $7 \mathrm{~h} .{ }^{37}$ However, in dogs, the plasma levels were inferior (between 2 and $15 \mathrm{mg} / \mathrm{L}$ ) for the same dose. ${ }^{38}$ In humans, the plasma levels after a single oral dose of $150 \mathrm{mg}$ rose to $10 \mathrm{mg} / \mathrm{L}$ during the first $5 \mathrm{~h}$ after administration. ${ }^{39}$ The half lethal dose $\left(\mathrm{LD}_{50}\right)$ of carprofen in mice is $282 \mathrm{mg} / \mathrm{kg}$ and in rats it is $149 \mathrm{mg} / \mathrm{kg}$. Carprofen has been used in humans at doses of up to $600 \mathrm{mg} / \mathrm{kg}$, being well tolerated. ${ }^{40}$ The results obtained in this work and the cited data suggest that carprofen or a lower-toxicity carprofen derivative (such as the recently developed reduced-toxicity IBP derivative $)^{41}$ could be developed as a useful anti-TB drug.

The synthetic derivatives obtained from IBP revealed that the free carboxylic acid group was essential for its mycobacterial growth inhibitory properties. The formation of either esters or amides was detrimental to in vitro activity. It was also noticed that the cytotoxicity of the amides and particularly of the esters increased dramatically compared with the free carboxylic acids. Therefore, in order to increase the potency of the 2-arylpropanoic acid class, any potential chemical modification should ideally be carried out on the aryl ring. Following this premise, nitration of IBP was envisaged as this substitution can be easily modified to generate other groups such as anilines and phenols. 3,5-Dinitro-IBP was more active than the parent compound, showing an MIC value around half that of IBP, while maintaining its relative cytotoxicity, as the SI had the same value (SI 13) for both compounds.

The growth curves of the three selected 2-arylpropanoic acids further confirmed that carprofen (7) was the most active growth inhibitor of slow-growing mycobacteria. In both experimental settings, either when the drugs were added at the time of inoculation or when the drugs were added in the early-exponential phase of growth, 7 (at $2 \times \mathrm{MIC}$ concentration) completely prevented (or arrested) the growth of $M$ bovis BCG. The CFU analysis demonstrated that this specific inhibitor was highly inhibitory when added in the lag phase of bacterial growth but did not affect bacterial viability when included at the exponential phase. This densitydependent antibacterial effect has been previously observed for omeprazole against Helicobacter pylori, being bactericidal when incubated from the start of the culture, but being bacteriostatic if added to the exponential-phase culture. ${ }^{42}$ It remains possible that several antibacterial drugs show this behaviour, a phenomenon which remains underexplored.

IBP (1), carprofen (7) and 3,5-dinitro-IBP (15) were all active against MDR clinical isolates. The members of the arylpropanoic class seem to inhibit the growth of slow-growing mycobacterial species by not interacting with the target proteins of first-line anti-TB drugs, namely InhA (or KasA), RpoB and EmbC. More interestingly, the 2-arylpropanoic acids were active against the 100-day old stationary $M$ bovis BCG culture, having the same MIC values as those obtained against the exponential-phase bacilli. However, the first-line anti-TB drugs INH and RIF increased their MIC values more than 100-fold against the stationary-phase bacteria compared with exponential-phase cultures. The tolerance to INH and RIF of this physiologically dormant state of mycobacteria has been repeatedly reported using different dormancy models. ${ }^{43-45}$ These results suggest that the 2-arylpropanoic acids target pathways associated with fundamental biological processes required in both the high and low metabolic states of intracellularly surviving mycobacterial pathogens.

The comparative bioinformatic approach used to propose potential targets of the 2-arylpropanoic class in $M$ tuberculosis suggested the translation initiation factor IF-2 $(\mathrm{Rv} 2839 \mathrm{c})$ protein $(\mathrm{InfB})$ as a possible endogenous target in mycobacteria. The InfB protein forms a complex with the first tRNA, which interacts specifically with $N$-formylmethionine, the first amino acid to be incorporated in nascent proteins. ${ }^{46}$ Therefore, InfB plays a crucial role in protein synthesis. The possibility that the 2arylpropanoic NSAIDs target protein synthesis is in agreement with the inhibition of both exponential and 
stationary-phase $M$ bovis BCG cells, as in the physiological stages of low metabolic activity, cells still need to synthesise proteins, a process which is deemed to occur at reduced rates compared with exponential-phase bacilli. ${ }^{47} 48$

The NSAID oxyphenbutazone has received recent attention for its activity against non-replicating $M$ tuberculosis, ${ }^{14}$ and therefore it is possible that NSAIDs share a common mechanism of action against the mycobacterial stages of low metabolic activity, a chemobiological feature that could be exploited for the introduction of a new generation of drugs against latent TB infection.

\section{Author affiliations \\ ${ }^{1}$ Department of Biological Sciences, Mycobacteria Research Laboratory, Institute of Structural and Molecular Biology, Birkbeck, University of London, London, UK \\ ${ }^{2}$ Department of Pharmaceutical and Biological Chemistry, UCL School of Pharmacy, London, UK \\ ${ }^{3}$ Department of Infection, Centre for Clinical Microbiology, Royal Free Campus, University College London, London, UK \\ ${ }^{4}$ Centre for Therapeutics Discovery, MRC Technology, London, UK}

Correction notice This paper has been corrected since it was first published. Affiliations 2 and 4 have been switched.

Acknowledgements The authors would like to thank Professor Simon Croft for his generous support with the TB culture facility at the London School of Hygiene and Tropical Medicine. We also thank Mr Emmanuel Samuel for his support in the acquisition of HRMS spectra.

Contributors SB conceived the project. DE prepared the 96-well plates with inhibitors or drugs for the HT-SPOTi assay at the Mycobacteria Research Laboratory (MRL) at Birkbeck using the MultidropCombi (Thermo-Fisher Scientific). Growth, maintenance and spot culturing of $M$ tuberculosis $\mathrm{H}_{37} \mathrm{Rv}$, $M$ bovis BCG, $M$ aurum, $M$ neoaurum, $M$ smegmatis $S$ aureus susceptible and EMRSA-16, E coli, $P$ putida and $R$ equi were carried out by JDG, DE and AG. MDR clinical isolates were grown and maintained by DE, SM and TDMH at the Centre for Clinical Microbiology, UCL Royal Free Hospital. The inhibitor library was purchased and provided by KB and BS at MRCT through an MTA. IBP derivatives were prepared by JDG, JM and SG at the UCL School of Pharmacy. AG performed the cytotoxicity and macrophage infection screening at Birkbeck. DE and JDG carried out the bioinformatic analysis. JDG, DE, BS and $S B$ were involved in experimental planning. JDG, DE, $K B$ and $S B$ were involved in the interpretation and analysis of results. JDG, DE and $S B$ produced the first draft and all the authors were involved in a critical reading and enhancing of the manuscript.

Funding This work was supported by the Medical Research Council, UK (New Investigators Research Grant, code: G0801956), Birkbeck Faculty of Science Research Grant and Birkbeck Translational Research Award to SB. JDG was sponsored by a Bloomsbury Colleges PhD Studentship.

\section{Competing interests None.}

Provenance and peer review Not commissioned; externally peer reviewed.

Data sharing statement Authors have sufficient dedicated network space available for storing, weeding, archiving and sharing research data (published and unpublished) including all experimental methods and results generated during the research project. These data are centrally backed up. All drug/inhibitor screening data are stored securely and shared with the research collaborators. Authors also use professional networking sites, such as ResearchGate, for sharing research experiences with other researchers worldwide. Research results will be incorporated into research-led teaching that the senior authors offer at the HE institutions. SB has a successful track record in engaging school students and organising public events in science, including presenting at the Science week and World TB events in London.

\section{REFERENCES}

1. Gandhi NR, Nunn P, Dheda K, et al. Multidrug-resistant and extensively drug-resistant tuberculosis: a threat to global control of tuberculosis. Lancet 2010;375:1830-43.

2. Swinney DC, Anthony J. How were new medicines discovered? Nat Rev Drug Discov 2011;10:507-19.

3. Bhakta S, Besra GS, Upton AM, et al. Arylamine $N$-acetyltransferase is required for synthesis of mycolic acids and complex lipids in Mycobacterium bovis BCG and represents a novel drug target. $J$ Exp Med 2004;199:1191-9.

4. Evangelopoulos D, Bhakta S. Rapid methods for testing inhibitors of mycobacterial growth. Methods Mol Biol 2010;642:193-201.

5. Guzman JD, Gupta A, Evangelopoulos D, et al. Anti-tubercular screening of natural products from Colombian plants: 3-methoxynordomesticine, an inhibitor of MurE ligase of Mycobacterium tuberculosis. J Antimicrob Chemother 2010;65:2101-7.

6. Anderton MC, Bhakta S, Besra GS, et al. Characterization of the putative operon containing arylamine $\mathrm{N}$-acetyltransferase (nat) in Mycobacterium bovis BCG. Mol Microbiol 2006;59:181-92.

7. Madikane VE, Bhakta S, Russell AJ, et al. Inhibition of mycobacterial arylamine $N$-acetyltransferase contributes to anti-mycobacterial activity of Warburgia salutaris. Bioorg Med Chem 2007;15:3579-86.

8. Van Klingeren B, Dessens-Kroon M, Van der Laan T, et al. Drug susceptibility testing of Mycobacterium tuberculosis complex by use of a high-throughput, reproducible, absolute concentration method. J Clin Microbiol 2007;45:2662-8.

9. Nzila A, Ma Z, Chibale K. Drug repositioning in the treatment of malaria and TB. Future Med Chem 2011;3:1413-26.

10. Chong CR, Sullivan DJ. New uses for old drugs. Nature 2007;448:645-6.

11. Amaral L, Boeree MJ, Gillespie SH, et al. Thioridazine cures extensively drug-resistant tuberculosis (XDR-TB) and the need for global trials is now! Int J Antimicrob Ag 2010;35:524-6.

12. Van Soolingen D, Hernandez-Pando $\mathrm{R}$, Orozco $\mathrm{H}$, et al. The antipsychotic thioridazine shows promising therapeutic activity in a mouse model of multidrug-resistant tuberculosis. PLOS ONE 2010;5: e12640.

13. Horita Y, Takii T, Yagi T, et al. Anti-tubercular activity of disulfiram, an anti-alcoholism drug, against multi-drug and extensively drug-resistant Mycobacterium tuberculosis isolates. Antimicrob Ag Chemother 2012;56:4140-5.

14. Gold B, Pingle M, Brickner SJ, et al. Nonsteroidal anti-inflammatory drug sensitizes Mycobacterium tuberculosis to endogenous and exogenous antimicrobials. PNAS 2012;109:16004-11.

15. Sanyal AK, Roy D, Chowdhury B, et al. Ibuprofen, a unique anti-inflammatory compound with antifungal activity against dermatophytes. Let Appl Microbiol 1993;17:109-11.

16. Elvers KT, Wright SJL. Antibacterial activity of the anti-inflammatory compound ibuprofen. Let Appl Microbiol 1995;20:82-4.

17. Byrne ST, Denkin SM, Zhang Y. Aspirin and ibuprofen enhance pyrazinamide treatment of murine tuberculosis. J Antimicrob Chemother 2007:59:313-16.

18. Pearce BC, Sofia MJ, Good AC, et al. An empirical process for the design of high-throughput screening deck filters. J Chem Inf Mode 2006;46:1060-8.

19. Gupta A, Bhakta S. An integrated surrogate model for screening of drugs against Mycobacterium tuberculosis. J Antimicrob Chemother 2012;67:1380-91.

20. Bushra R, Aslam N. An overview of clinical pharmacology of Ibuprofen. Oman Med J 2010:25:155-1661.

21. Gasparini L, Ongini E, Wilcock D, et al. Activity of flurbiprofen and chemically related anti-inflammatory drugs in models of Alzheimer's disease. Brain Res Rev 2005;48:400-8.

22. Raz A. Is inhibition of cyclooxygenase required for the anti-tumorigenic effects of nonsteroidal, anti-inflammatory drugs (NSAIDs)?: in vitro versus in vivo results and the relevance for the prevention and treatment of cancer. Biochem Pharmacol 2002;63:343-7.

23. Lleo A, Galea E, Sastre M. Molecular targets of non-steroidal anti-inflammatory drugs in neurodegenerative diseases. Cell Mol Life Sci 2007;64:1403-18.

24. Lew JM, Kapopoulou A, Jones LM, et al. TubercuList-10 years after. Tuberculosis 2011;91:1-7.

25. Peng L, Wang B, Ren P. Reduction of MTT by flavonoids in the absence of cells. Colloids Surf B 2005;45:108-11.

26. O'Brien J, Wilson I, Orton T, et al. Investigation of the Alamar Blue (resazurin) fluorescent dye for the assessment of mammalian cell cytotoxicity. Europ J Biochem 2000;267:5421-6. 
27. Yao M, Zhou W, Sangha S, et al. Effects of nonselective cyclooxygenase inhibition with low-dose ibuprofen on tumor growth, angiogenesis, metastasis, and survival in a mouse model of colorectal cancer. Clin Cancer Res 2005;11:1618-28.

28. Konstan MW, Krenicky JE, Finney MR, et al. Effect of ibuprofen on neutrophil migration in vivo in cystic fibrosis and healthy subjects. J Pharmacol Exp Ther 2003;306:1086-91.

29. McElwee NE, Veltri JC, Bradford DC, et al. A prospective, population-based study of acute ibuprofen overdose: complications are rare and routine serum levels not warranted. Ann Emerg Med 1990;19:657-62.

30. Hall AH, Smolinske SC, Conrad FL, et al. Ibuprofen overdose: 126 cases. Ann Emerg Med 1986;15:1308-13.

31. Graham GG, Williams KM. Metabolism and pharmacokinetics of ibuprofen. In: Rainsford KD, ed. Aspirin and related drugs. CRC Press, 2004.

32. Stratman NC, Carter DB, Sethy VH. Ibuprofen: effect on inducible nitric oxide synthase. Mol Brain Res 1997;50:107-12.

33. Stuhlmeier KM, Li H, KaO JJ. Ibuprofen: new explanation for an old phenomenon. Biochem Pharmacol 1999;57:313-20.

34. Arriaga AK, Orozco EH, Aguilar LD, et al. Immunological and pathological comparative analysis between experimental latent tuberculous infection and progressive pulmonary tuberculosis. Clin Exp Immunol 2002;128:229-37.

35. Kuo HP, Wang $\mathrm{CH}$, Huang $\mathrm{KS}$, et al. Nitric oxide modulates interleukin-1 $\beta$ and tumor necrosis factor- $\alpha$ synthesis by alveolar macrophages in pulmonary tuberculosis. Am J Respir Crit Care Med 2000:161:192-9.

36. Fox SM, Johnston SA. Use of carprofen for the treatment of pain and inflammation in dogs. J Am Vet Med Assoc 1997;210:1493-8.

37. Taylor PM, Delatour P, Landont FM, et al. Pharmacodynamics and enantioselective pharmacokinetics of carprofen in the cat. Res Vet Sci 1996;60:144-51.

38. McKellar QA, Delatour P, Lees P. Stereospecific pharmacodynamics and pharmacokinetics of carprofen in the dog. $J$ Vet Pharmacol Ther 1994;17:447-54.
39. Spahn H, Spahn I, Benet LZ. Probenecid-induced changes in the clearance of carprofen enantiomers: a preliminary study. Clin Pharm Ther 1989;45:500-5.

40. EAEMP. Carprofen summary report. Committee for veterinary medicinal products: The European Agency for the Evaluation of Medicinal Products, 1995

41. Xie G, Sun Y, Nie T, et al. Phospho-ibuprofen (MDC-917) is a novel agent against colon cancer: efficacy, metabolism, and pharmacokinetics in mouse models. J Pharmacol Exp Ther 2011;337:876-86.

42. Mirshahi F, Fowler G, Patel A, et al. Omeprazole may exert both a bacteriostatic and a bacteriocidal effect on the growth of Helicobacter pylori (NCTC 11637) in vitro by inhibiting bacterial urease activity. J Clin Pathol 1998;51:220-4.

43. Deb C, Lee CM, Dubey VS, et al. A novel in vitro multiple-stress dormancy model for Mycobacterium tuberculosis generates a lipid-loaded, drug-tolerant, dormant pathogen. PLOS ONE 2009;4: e6077.

44. Bartek IL, Rutherford R, Gruppo V, et al. The DosR regulon of $M$. tuberculosis and antibacterial tolerance. Tuberculosis 2009;89:310-16.

45. Sriram D, Yogeeswari P, Dhakla P, et al. 5-Nitrofuran-2-yl derivatives: synthesis and inhibitory activities against growing and dormant Mycobacterium species. Bioorg Med Chem Let 2009;19:1152-4.

46. Guenneugues M, Caserta E, Brandi L, et al. Mapping the fMet-tRNAfMet binding site of initiation factor IF2. EMBO $J$ 2000;19:5233-40.

47. Yuan Y, Crane DD, Barry CE. Stationary phase-associated protein expression in Mycobacterium tuberculosis: function of the mycobacterial alpha-crystallin homolog. $J$ Bacteriol 1996;178:4484-92.

48. Hu YM, Butcher PD, Sole K, et al. Protein synthesis is shutdown in dormant Mycobacterium tuberculosis and is reversed by oxygen or heat shock. FEMS Microbiol Let 1998;158: $139-45$. 